\title{
Reestruturação produtiva e recomposições do trabalho e emprego. Um périplo pelas "novas" formas de desigualdade social
}

\author{
Productive restructuring and the reallocation of work \\ and employment. A survey of the "new" forms of social inequality
}

${ }^{1}$ Departamento de Sociologia, Instituto de Ciências Sociais,

Universidade do Minho. Campus de Gualtar. 4710-057 Braga Portugal. amarques@ics.uminho.pt
Abstract The scope of this paper is to question the inevitability of the processes of segmentation and increased precariousness of the relations of labor and employment, which are responsible for the introduction of "new" forms of social inequality that underpin the current model of development of economies and societies. It seeks to criticize the limits of global financial and economic logic, which constitute a "new spirit of capitalism," namely a kind of reverence for the natural order of things. It is therefore necessary to conduct an analytical survey of the ongoing changes in the labor market, accompanied by epistemological vigilance which makes it possible to see neoliberal (di)visions and dominant technodeterministic theses in context. The enunciation of scenarios on the future of work will conclude this survey and will make it possible to draw attention to both the historical and temporal constraints and to the urgent need to unveil what is ideological and political in the prevailing logic of rationalization and processes to reinstate work and employment as a "central social experience" in contemporary times.

Key words Labor market segmentation, Flexible employment routines, Social inequalities
Resumo O propósito do presente artigo consiste em questionar a inevitabilidade dos processos de segmentação e precarização das relações de trabalho e emprego, responsáveis pela inscrição de "novas" formas de desigualdade social que alicerçam o actual modelo de desenvolvimento das economias e sociedades. Visa-se criticar os limites da lógica econômica e financeira, de contornos globais, que configuram um "novo espírito do capitalismo", ou seja, uma espécie de divinização da ordem natural das coisas. Impõe-se fazer, por isso, um périplo analítico pelas transformações em curso no mercado de trabalho, acompanhado pela vigilância epistemológica que permita enquadrar e relativizar as (di)visões neoliberais e teses tecnodeterministas dominantes. A perspectivação de cenários sobre o futuro do trabalho encerrará este périplo, permitindo-nos alertar para os condicionalismos histórico-temporais, para a urgência de se desocultar o que de ideológico e político existe nas actuais lógicas de racionalização e para os processos de ressimbolização do trabalho e emprego enquanto "experiência social central" na contemporaneidade.

Palavras-chave Segmentação do mercado de trabalho, Formas flexiveis de emprego, Desigualdades sociais 


\section{Introdução}

A "sacralização" do mercado assume-se, hoje, como ideário de justificação das transformações observadas ao nível dos sistemas econômico, político e social, com inequívocas consequências nas relações de e no trabalho e emprego. A imposição de uma lógica econômica e financeira, de contornos globais, configura um "novo espírito do capitalismo"1, ou seja, uma espécie de divinização da ordem natural das coisas. Convertidos em "absolutos sociais", os princípios de produtividade e competitividade assumem a força da retórica discursiva e política, com inscrição nas práticas sociais, pelo que o mercado de trabalho e, muito em especial, a "força de trabalho" se convertem numa mercadoria como qualquer outra. Por sua vez, a desregulação do mercado de trabalho e a perda das conquistas laborais do século XX, com particular impacto nos diversos grupos sociais, são condições indispensáveis para a institucionalização de um regime de acumulação flexível e de uma "adequada" regulação social ${ }^{2-10}$. O essencial desta argumentação tem sido no sentido de assumir a correspondência do "fim do trabalho" ao "fim do trabalho estável”, fruto das exigências de flexibilidade do mercado de trabalho e da polivalência dos trabalhadores. No limite, significa que se reivindica como condição indispensável de funcionamento daquele mercado a sua própria desregulação, instabilidade e exteriorização das condições de reprodução dos actores sociais.

Com efeito, desde a crise petrolífera dos anos setenta do século XX, as sociedades contemporâneas enfrentam fenômenos diversos, tais como: deslocalizações das empresas (dumping social); desregulação da relação salarial; difusão de formas flexíveis e "atípicas" de emprego; expansão do sector informal e clandestino (sobreexploração); desemprego estrutural; polivalência desqualificante; práticas androcêntricas de discriminação do mercado de trabalho; (re)organização dos tempos de "trabalho" e "não-trabalho. Muitos destes fenômenos têm a sua origem nas dinâmicas econômicas, políticas, educativas, simbólicas, entre outras. Porém, é o mercado de trabalho que, ao utilizar, (re)produzir e transpor para o espaço de trabalho e de emprego esses fenômenos, perpetua-os, reforça-os ou cria "novas" diferenciações sociais. Neste sentido, emergem vários actores sociais, para além do grupo profissional corporizado no "operário-massa”, como sejam, por exemplo, as mulheres que acedem ao mercado de trabalho, ou os trabalhadores independentes, ou os jovens quadros, ou os precários, estagiário e bolseiros, que partilham entre si uma crescente vulnerabilidade e precariedade, incluindo vivência de experiências de desemprego e inactividade constrangida. Estes grupos sociais diversificados e heterogéneos, tradicionais e novos, (re)configuram o mercado de trabalho. Das lógicas diversas que sustentam a divisão social do trabalho, sejam elas de vínculos laborais, de género, de nível de qualificação académica, de idade, entre outras, as consequências sociais destas recomposições apresentam-se, em certa medida, (in)visíveis nos domínios profissional e familiar/privado da acção social. Além disso, as modalidades actuais de vinculação ao trabalho e emprego assumem dimensões de opacidade, insegurança e ruptura face quer à crescente fragmentação das "categorias de identificação indígenas"11, quando estes se (re)vêem como trabalhadores “estáveis", "precários”, "prestadores de serviços", "estagiários" e "bolseiros"..., quer às suas condições de progressão profissional individualizadas, subjetivas e incertas ${ }^{12,13}$.

\section{Considerações metodológicas}

Questionar a inevitabilidade destes processos de segmentação e precarização das relações de trabalho e emprego, que têm vindo a alicerçar o actual modelo de desenvolvimento das sociedades e economias ocidentais, constitui o propósito do presente artigo. Propõe-se, por conseguinte, um ensaio crítico onde se dialoga com os autores que se debruçaram direta e indiretamente sobre a temática da reestruturação produtiva e as "novas" formas de desigualdade social. Com efeito, não só falta um consenso sobre as transformações ao nível dos modelos produtivos e organizacionais, do trabalho e emprego, como somos interpelados a reflectir sobre os seus cenários de evolução de modo a se ultrapassar as (de)visões neoliberais e teses tecno-deterministas dominantes. Na verdade, ainda que haja algum conhecimento sobre as transformações em curso, este apresenta-se insuficiente para uma reflexão consistente sobre a problemática das consequências do ponto de vista econômico e social em geral, bem como da qualidade de vida no trabalho e das condições para o exercício de uma cidadania activa e responsável.

Este artigo iniciar-se-á com uma discussão em torno do impacto da globalização e das novas tecnologias de informação e comunicação nas opções de modelos organizacionais flexíveis. As mudanças em curso fazem-se no quadro de 
uma crescente privatização de serviços e desregulamentação de certas garantias sociais, acompanhado pela difusão de forma flexíveis e "atípicas” no quadro das relações de trabalho. Finaliza-se com a enunciação de alguns cenários sobre o futuro do trabalho que nos permite alertar quer para os condicionalismos histórico-temporais, quer para a urgência em se desocultar o que de ideológico e político existe nas actuais lógicas de racionalização e organização do trabalho, quer, ainda, para os processos de ressimbolização do trabalho e emprego enquanto "experiência social central" na contemporaneidade.

\section{Economia global, competitividade e (não) uni-direccionalidade das reestruturações produtivas}

É inquestionável que a actual problemática do "mundo de trabalho", no seu sentido mais abrangente, assume contornos novos à luz do processo de globalização, fruto da intensificação das relações sociais à escala planetária ${ }^{14}$. Se, em termos analíticos, não há propriamente um consenso em torno da globalização e dos seus impactos $^{15}$, entende-se por economia global quando esta tem capacidade para funcionar como uma unidade em tempo real numa escala planetária. Tal só foi possível efetivamente no final do século XX, com a difusão das Tecnologias de Informação e Comunicação (TIC) no sentido mais abrangente. Por sua vez, são manifestas as dimensões de globalização financeira e econômica, acompanhadas por estratégias claras de liberalização dos capitais e fluxos de informação, de privatização dos sectores e actividades econômicas, de desregulamentação, afectando em especial o welfare State, e de práticas de flexibilização a vários níveis do sistema produtivo e educativo, sobretudo, a partir dos anos oitenta do séc. XX.

São justamente as exigências de inovação constante do produto/processo, além da procura de competitividade e qualidade no contexto da economia globalizada, que explicam os processos de reestruturação produtiva e os seus reflexos na organização do trabalho. Os modelos de produção flexível associam-se a uma economia pós-industrial, em que a indústria e os serviços convergem para um sistema produtivo complexo, intensivo em capital, orientado para a qualidade e a flexibilidade. Para este desígnio, as TIC, com novas potencialidades (maior performance econômica, produzindo produtos diversificados, frequentemente renovados com a melhoria de produtividade e qualidade), explicam, em gran- de medida, as profundas transformações nos conteúdos das actividades profissionais, no perfil de qualificações, nos modelos de organização do trabalho e gestão empresarial, no "rosto" das modalidades de emprego e, de um modo geral, na qualidade de vida dos trabalhadores. Como corolário deste processo, destacam-se, a partir dos anos oitenta, os novos valores face ao trabalho e ao emprego, com ênfase nas qualidades e atributos do futuro trabalhador (e.g. responsável, autônomo, criativo, participativo, adaptativo, empreendedor $)^{16}$.

Porém, não há propriamente um consenso generalizado em torno dos modelos produtivos em desenvolvimento nas atuais realidades empresariais $^{9,17}$. Apoiadas na desburocratização, desmaterialização de processos e valorização do capital humano, as novas arquitecturas organizacionais e os princípios de gestão empresarial enraízam-se em estruturas mais descentralizadas, no enriquecimento do conteúdo do trabalho, na melhoria da comunicação e do relacionamento interpessoal e na motivação dos trabalhadores. $\mathrm{Na}$ verdade, muitas destas propostas já foram avançadas pela corrente sociotécnica, sendo retomadas, atualmente, sob a forma de novas designações como, por exemplo, gestão por objectivos, qualidade total, descentralização e desconcentração, autonomia e responsabilidade dos trabalhadores.

O que é um facto é que depois da crise vaticinada do modelo taylorista-fordista (racional-burocrático), este persiste ainda, embora combinado com as novas tecnologias e os modelos organizacionais atrás enunciados. O movimento de reestruturação da maioria das empresas no sentido de uma revitalização empresarial (em empresas "excelentes" como, por exemplo, a IBM e a Macdonalds) conjuga-se com a difusão de vários modelos flexíveis de empresa (e.g. downsizings, justin-time, outsourcing). Na tentativa de contemplar uma visão realista e crítica das mudanças em curso, Kovács e Castilho ${ }^{17}$ sistematiza quatro cenários possíveis face às reestruturações produtivas: 1) neotaylorismo em direcção a uma sociedade dual; 2) neotaylorismo em direcção a uma sociedade segmentada; 3 ) lean production em direcção a uma sociedade hipercompetitiva; 4) antropocentrismo em direcção a uma sociedade democrática e equitativa. Não se registando um consenso sobre que modelo de produção possa garantir a competitividade, a autora conclui que os processos de reestruturação empresarial têm seguido, todavia, uma lógica geral próxima do modelo lean production (modelo japonês). 
Não obstante não ser possível aceitar uma não uni-direccionalidade dos modelos produtivos, a centragem no factor competitividade e qualidade total, a par de uma gestão da cultura da empresa baseada em trabalhadores competentes, disponíveis e flexíveis, cooperativos e responsáveis, apresenta-se como uma das tendências centrais que caracterizam as economias contemporâneas. A maior divulgação pelo modelo flexível de produção, apesar de possíveis combinações, é relevante para se compreender as actuais tendências gestionárias e empresariais que têm ocasionado alterações no volume de empregos e correlativamente na composição do desemprego (tornando-se estrutural), no perfil de qualificação dos trabalhadores, nos padrões de gestão da força de trabalho, nas relações interempresas, entre outras. Neste contexto, as opções em termos de estratégias de flexibilização quantitativa e técnica, como veremos a seguir, têm conduzido a uma "autoexploração" ou a "formas subtis de dominação" dos trabalhadores, agravando as atuais condições de trabalho ${ }^{18,19}$. Entre as consequências negativas podem ser referidas estão a intensificação do ritmo de trabalho, a marginalização dos trabalhadores com menores competências, a degradação das condições de trabalho e de contratação e, no limite, da qualidade de vida no trabalho, para além de se comprometer as condições de um exercício de cidadania activa e responsável.

É indiscutível que o processo de transformação do "mundo do trabalho" nas últimas décadas se apresenta bastante contraditório: nalguns casos conduz a uma (re)valorização do trabalho e investimento na formação e qualidade de vida dos trabalhadores; noutros, porém, desvaloriza o trabalho e deteriora o emprego e as condições de participação nos colectivos de trabalho. Estes movimentos apresentam-se selectivamente desiguais, já que variam em função do sector econômico, do tipo e dimensão da empresa, da organização interna da empresa e, em particular, das práticas de gestão de recursos humanos seguidas, ou seja, das categorias profissionais e sociais que fazem parte da configuração das sociedades contemporâneas.

De tudo o que temos vindo a argumentar, reitera-se que esta nova fase de desenvolvimento do capitalismo, incluindo transformações estruturais na natureza do capital e da produção, projectam uma reconversão política e econômica associada a uma reconversão ideológica de cariz neoliberal para legitimar o modelo actual de globalização do mercado de capitais, de tecnologia e produtos e, por último, da força de trabalho. Tal reconversão se assenta no estilhaçamento progressivo, de forma objectiva e subtil, das conquistas sociais dos trabalhadores nas últimas décadas ${ }^{20}$. De forma objectiva, trata-se das alterações no corpus legal de direitos reconhecidos em relação ao trabalho e às obrigações do Estado face aos trabalhadores. De forma subtil, trata-se da destruição de culturas de trabalho, no sentido lato, que os diversos colectivos de trabalhadores modelaram, como resultado de suas experiências ao longo das últimas décadas, em contextos de trabalhos específicos e com base em relações concretas de produção e reprodução.

\section{Terciarização e dinâmicas \\ profissionais/estatutárias heterogêneas}

Os efeitos da terciarização da economia na estrutura profissional, em particular no surgimento de novas divisões internas entre os trabalhadores, e nas exigências de outros perfis de qualificação inscrevem-se numa das tendências mais longas das últimas décadas para a maioria dos países ocidentais. $\mathrm{O}$ aumento do peso das actividades relacionadas com os transportes, o comércio, os serviços e a investigação, bem como o aparecimento de actividades de utilidade social, proximidade e desenvolvimento local e regional explicam, assim, a importância actual do sector terciário na economia mundial.

É indiscutível que na base desta transformação está o desenvolvimento tecnológico e científico que permitiu ao homem obter uma grande produção de bens agrícolas e industriais, utilizando cada vez menos mão-de-obra. Mas também resultou de um movimento mais abrangente que se prendeu com o êxodo rural motivado pela procura de trabalho, primeiro na indústria e depois no comércio e serviços, com o envelhecimento da população agrícola e a fraca capacidade atractiva deste sector (muito trabalho e pouco rendimento) e, mais recentemente, com o crescimento do sector público e da profissionalização de diversos corpos e grupos profissionais sancionados por diplomas emanados pelas diversas instituições de educação e formação.

Genericamente, é consensual aceitar-se que estamos perante um movimento de transformação significativa da estrutura ocupacional fruto de processos de recomposição da mão-de-obra, com a eliminação e/ou redução de postos de trabalho, a par de reformulação de referentes de emprego/profissão mais abrangentes e integrados. A criação de novos postos de trabalho ligados às funções de planeamento, concepção, pro- 
gramação e de manutenção dos novos equipamentos, ao mesmo tempo em que as tarefas de carácter repetitivo e rotineiro são progressivamente eliminadas, permitindo criar diferentes segmentos de força de trabalho, respondem pelo acentuar da heterogeneidade e fragmentação estatutária que atravessam os colectivos de trabalho na atualidade.

Neste jogo de forças, os "perdedores" são os trabalhadores excluídos deste processo de modernização produtiva, ao passo que os "ganhadores" são os que controlam o sector da informação e conhecimento ${ }^{21}$, reforçando-se a tendência para a crescente divisão entre trabalho qualificado e não qualificado e para o aumento do trabalho pouco qualificado no contexto da economia global. Este é, de resto, um contributo relevante avançado por Reich ${ }^{22}$ quanto à alegada generalização do trabalho qualificado na era da informação e conhecimento. Segundo o autor, integram-se, naquele grupo de "perdedores", os que ficarão confinados ao exercício de actividades que têm em comum o facto de não produzirem valor acrescentado, designadamente "serviços de rotina" e "serviços interpessoais". Incluem-se nos "serviços de rotina" trabalhadores que executam tarefas repetitivas manuais, desde os "colarinhos azuis", os gestores de médio e baixo nível (como os capatazes, gestores de linha, chefes de escritórios e de secção), aos que, na "era informacional", se dedicam a tarefas monótonas, como os processadores de dados instalados em escritórios cada vez mais invisíveis, trabalhando a partir de casa ou em espaços públicos (e.g. teletrabalho, call-centers, coworkers). Por sua vez, os trabalhadores que integram os serviços interpessoais desenvolvem a sua actividade fundamentalmente em contacto com os clientes e incluem uma diversidade de actividades: venda a retalho, recepcionistas, porteiros, vigilantes, segurança, amas, cuidadores, educadoras de infância, trabalhadores de limpeza doméstica, motoristas, vendedores de imobiliários, entre outros.

No grupo dos "ganhadores" estão as actividades desempenhadas pelos "analistas simbólicos" que incluem todas as actividades de identificação e resolução de problemas e encontram-se, em regra, associados a padrões elevados de rendimento e de prestígio social. Apesar de existirem diferenciações internas neste grupo, os analistassimbólicos são, em geral, licenciados ou têm formação pós-graduada e o seu rendimento e prestígio dependem da sua criatividade e capacidade de inovação e resolução de problemas. De certa forma, este grupo pode ser comparado a uma "elite profissional"23 altamente qualificada que fundamenta a sua actuação e carreira numa escala mundial. Neste grupo de trabalhadores encontram-se, sobretudo, investigadores científicos, gestores e quadros de direcção de topo nos segmentos de produção de valor acrescentado (e.g. advogados, engenheiros, relações públicas), analistas de sistemas, designers e estrategas de marketing, comunicação e imagem, entre outros.

Reforçando a dimensão socioeconômica e a esfera produtiva na organização das desigualdades e oportunidades dos indivíduos, Estanque ${ }^{23}$ enuncia algumas das linhas de recomposição social com implicações em todos os níveis da pirâmide social: desde as elites profissionais, empresariais e institucionais às camadas mais excluídas e proletarizadas, passando pelos segmentos intermédios das chamadas "novas classes médias". Estes novos contornos das desigualdades sociais são, por isso, visíveis nas situações de precariedade, acompanhadas por uma crescente "atipicidade" laboral, relações de subemprego e desemprego resultantes das actuais tendências de globalização econômica e de fragmentação dos sistemas de trabalho. Ao mesmo tempo, reforça-se a pirâmide social com uma "nova elite socioprofissional e institucional que monopoliza conhecimentos, competências, informação, redes sociais, movendo-se a uma escala planetária" ${ }^{\text {23 }}$. Falamos da mobilidade de directores de grandes multinacionais, gestores de topo, funcionários das instituições do Estado, quadros altamente qualificados, dirigentes políticos, cientistas de renome, entre outros. Apesar da diversidade de sectores envolvidos, estes trabalhadores poderão formar uma "sobre classe global" visto posicionarem-se acima da velha classe dominante tradicional ${ }^{23}$.

Estes fenômenos traduzem, sobretudo, uma ampliação e intensificação dos processos de estruturação das desigualdades e das classes sociais, passando-se a situá-los a uma escala nacional, mas também transnacional, ao mesmo tempo que se acentuam os níveis de complexidade associados. Estes resultam de processos de instabilidade, fragmentação e reconversão das diferentes posições de classe que fazem parte das recomposições do mercado de trabalho, em articulação com o sistema de ensino e formação, o Estado e a sociedade em geral.

\section{Flexibilização, precarização e segmentação das relações laborais}

Exigências de flexibilidade e contrapartidas de natureza política, traduzidas na desregulação das 
relações laborais, introduzem importantes transformações nas lógicas de funcionamento dos mercados de trabalho. Como referimos atrás, o enfraquecimento de certos referentes do Estadoprovidência, como a estabilidade de emprego e a garantia de certos direitos/concessões profissionais, tem sido uma parte significativa da resposta avançada por muitos dos governos actuais. O trabalho, no seu conteúdo e significado social, tende a ser metamorfoseado sob um registo e discurso neoliberal ${ }^{2,3}$, operando-se uma reconversão ideológica em expansão na Europa e no mundo ${ }^{20}$.

Para a sustentação desta reconversão ideológica, impõe-se avançar com os seguintes argumentos. Antes de mais, apesar de não serem lineares, são diversas as práticas de flexibilidade dos recursos humanos adoptadas pelas organizações em Portugal, como nos restantes países da Europa. Estas formas flexíveis de emprego ${ }^{2,24-27}$ podem ser constituídas, designadamente, por contratos de trabalho de duração determinada (a termo certo e incerto), contratos de trabalho temporário, contratos de trabalho a tempo parcial (part-time), trabalho independente ou autoemprego e mais, recentemente, empreendedorismo.

Neste domínio, segundo as estatísticas oficiais disponíveis (INE e EUROSTAT), Portugal apresentou, em 2010, uma percentagem de contratos não permanentes (de duração limitada) superior (23\%) à média europeia dos 27 Estados-Membros (14\%). Igualmente, a taxa de emprego a tempo parcial é, no total da população ativa, $11,6 \%$, contra uma média europeia de $19,2 \%$. A relação contratual independente, sendo normalmente ilustrada como trabalhador a "recibos verde", assume a percentagem de 16,7\% em Portugal, o que é superior considerando a média europeia $(10,7 \%)$. A acrescentar a estes indicadores de vulnerabilização e precarização das relações de trabalho, importa não esquecer a tendência para um aumento significativo da taxa de desemprego, sobretudo a partir de 2003/04, atingindo, no $1^{\circ}$ trimestre de $2012,13 \%$, sendo a terceira taxa mais elevada dos 27 Estados-Membros. Estes traços evidenciam, ainda, uma selectividade significativa: há uma maior incidência das formas atípicas ou flexíveis de emprego, bem como do desemprego, junto de jovens qualificados e não qualificados, de mulheres, de trabalhadores com qualificações obsoletas e com idades mais avançadas. Estas tendências de fundo têm sido analisadas e aprofundadas em investigações empíricas realizadas por nós, com particular destaque para as recomposições do mercado de trabalho de jovens graduados pelo Ensino Superior ${ }^{20,28-32}$.
Por sua vez, é crucial perceber que o entendimento em torno da expressão de "flexibilidade" não se tem apresentado consensual, prestandose a algumas ambiguidades quando utilizado sem uma prévia delimitação do seu alcance semânti$\mathrm{co}^{10,33,34}$. Para além das vantagens e/ou inconvenientes desta flexibilidade (depende sempre do ponto de vista de quem as interpreta) importa destacar duas tendências a reter: primeira, a desregulamentação desejada (pelos empregadores fundamentalmente) da protecção ao emprego; segunda, a precariedade das relações de trabalho, com consequências na (re)produção de processos de segmentação e diferenciação do emprego e salário, a par da tendência para a fragmentação das relações profissionais e de coesão social.

Assim, de modo consensual, associa-se geralmente a ideia de precariedade à multiplicação de empregos "atípicos" ou fora da norma, à maior vulnerabilidade nas relações laborais porque instáveis, e ao desenvolvimento do desemprego. Definiu-se a norma do emprego (por tempo indeterminado, a tempo inteiro e com proteção social) como o perfil do que social e juridicamente se convencionou designar como emprego assalariado "típico". Nesta linha de pensamento, as formas "atípicas" ou precárias de emprego e trabalho afastam-se do modelo de assalariamento dominante no período pós II Guerra Mundial que se alicerçava na estabilidade de emprego, concertação coletiva e na observância de critérios, como: i) a durabilidade da relação de emprego; ii) a unicidade do empregador e pertença a um serviço organizado; iii) e o horário a tempo inteiro com salário equivalente ${ }^{35}$. Desta forma, tem-se vindo a estabelecer uma certa reciprocidade entre os designados "empregos atípicos" e os "empregos precários". O que nos parece plausível sustentar, para já, é que nem todos os empregos "atípicos" são empregos "precários", pelo que estas expressões podem não ser totalmente equivalentes, mesmo se os dois atributos geralmente se conjugam. Pode admitir-se que estas novas formas de trabalho constituem uma escolha para alguns trabalhadores $^{30} \mathrm{e}$, portanto, sejam destituídas do carácter de imposição e constrangimento inerentes à noção de precariedade. Por sua vez, importa referir que, actualmente, também as formas de emprego "típicas" conhecem evoluções do contrato de trabalho, tais como a individualização de remunerações, desempenho profissional e carreiras e gestão por projectos e objectivos, entre outras, que contribuem, igualmente, para sentimentos de insegurança e incerteza quanto ao futuro do trabalhador na empresa. Em determinadas circunstân- 
cias, estas características podem desembocar em situações de trabalho precárias por via, nomeadamente, de um acréscimo dos constrangimentos e da subordinação real, não obstante um alegado esbatimento da subordinação formal. Também a ideia de estabilidade deve ser encarada com cuidado quando reduzida a um emprego "típico" cujo conteúdo de trabalho executado apresentase pobre e desqualificado, sendo maior a exposição a uma situação de risco de desemprego.

Por outro lado, a noção de precariedade tem sido dominantemente representada e analisada como precariedade do emprego, remetendo, no essencial, para a existência de empregos incertos, contratos de trabalho de curta (ou pelo menos determinada) duração e para uma restrição, efectiva ou potencial, dos direitos sociais. Neste contexto, o tipo de contrato de trabalho tende a ser o factor determinante na definição da precariedade.

Ora, não só é necessário, como vimos, distinguir nos empregos atípicos aqueles que o são com um carácter voluntário daqueles que não o são, como é importante não restringirmos as dimensões da precariedade às condições jurídico-institucionais, que nos remetem para os indicadores do tipo de contrato de trabalho e remuneração. O que nos parece importante, e convém reforçálo, é assumir a não exclusividade daquele argumento, convocando outras dimensões relacionadas com os conteúdos, os saberes e as competências e as condições de exercício da actividade profissional, para além do conjunto de representações e expectativas produzidas a partir do contexto de trabalho. Assim sendo, num esforço de identificação das várias dimensões da precariedade, exige-se a mobilização de vários indicadores, como sejam, por exemplo, os ritmos e intensidade do tempo de trabalho, a previsibilidade dos horários, o grau de autonomia e de responsabilidade na execução das tarefas, as redes relacionais, o grau de satisfação com o trabalho, as representações do trabalho, o projecto profissional e pessoal e o impacto do emprego nas outras esferas da vida pública/privada dos actores sociais.

Desta forma, fundamenta-se o conceito de precariedade sob o ângulo da insegurança econômica e social, como também sob o ângulo do tipo de trabalho, da retribuição material e simbólica da energia despendida em contexto de trabalho e dos quadros de interacção social e valorativos associados ${ }^{36}$. Por outras palavras, incluise igualmente, a dimensão estruturante de socialização e de integração socioprofissional decorrente da relação com o trabalho.

\section{Que cenários para o "futuro do trabalho"?}

A ruptura da figura do "trabalhador colectivo" torna-se cada vez mais evidente, fragmentando-se em grupos sociais com oportunidades e possibilidades cada vez mais diferenciadas, face ao mundo do trabalho e à inserção na sociedade global. Esta exaltação da individualização das relações de trabalho pela centralidade que a empregabilidade assume no cômputo das políticas públicas de emprego, formação e educação, concretiza-se na profecia de que cada um dos indivíduos é responsável pelo seu projecto de carreira e de vida. Se passarmos deste plano de retórica impregnada de uma ideologia neoliberal, para um plano próximo da realidade, a precarização do emprego, a degradação das condições de trabalho e a insegurança e intensificação do trabalho ${ }^{37}$ contribuem para a desintegração das colectividades de trabalho. A um plano simbólico e valorativo, a configuração de identidade(s) profissional(ais) dos trabalhadores dependerá em muito da sua vivência do trabalho, do que fazem e do que gostariam de fazer, das trajectórias socioprofissionais e das relações estabelecidas com a formação ${ }^{11}$. Nesta mesma linha de registo, assistemse a processos de (des)ajustamentos identitários num contexto de "nomadismo" enfatizado pela mobilidade profissional e pelo trabalhador empresário e "líder de si mesmo" expostos aos diferentes riscos associados às dinâmicas dos mercados de trabalho, como atrás referimos.

Porém, sobre estes processos de recomposição e selectividade do mercado de trabalho que parecem impor uma nova organização econômica e social, são questionáveis as (di)visões neoliberais ou os debates alimentados através de algumas teses a propósito da "descentração" 38 do valor do trabalho, do "fim do trabalho"39, da "crise do trabalho" 40 e da "exclusão socioprofissional dos desempregados" ${ }^{41}$. Desde posições otimistas, pessimistas, fatalistas a pretensiosamente neutras, encerradas numa argumentação sobre tecnologia e emprego, tecnologia e classe social, o debate mantém-se até aos dias de hoje. É relevante perceber que neste debate os autores partem de pressupostos diferenciados, uns mais próximos de lógica gestionária e economicista que preconiza a autorregulação do mercado de trabalho; outros mais próximos de perspectivas críticas da relação entre capital e trabalho. Pensamos que esta diversidade de posições permite contrariar a ideia de que se está perante tendências uniformes e inelutáveis relativas a esta temática. 
O consenso que se generalizou em torno quer da redução do emprego estável (típico), quer da expansão de modalidades diferenciadas de vínculos contratuais, remunerações, horários, formação e garantias sociais, entre outras, quer, ainda, da fragmentação e desmaterialização da produção e locais de trabalho (empresa "flexível" ou "magra") tem sido o suporte daquelas posições que saem reforçadas no actual contexto de globalização e competitividade. Todavia, ambas incorrem na tentação de generalização e inevitabilidade das tendências atrás apresentadas, descurando a heterogeneidade e a diferenciação que afectam a evolução do trabalho e emprego.

Nesta linha de argumentação, Kovács ${ }^{3}$, numa tentativa de síntese, apresenta quatro "cenários para a evolução do trabalho" (Quadro 1) ancorados em dois eixos: $i$ ) um que se estrutura na centralidade do trabalho (remunerado) ou na centralidade de actividades alternativas (próximas do que se entende por actividades de "terceiro sector"); ii) outro centrado na regulação social ou no mercado. Da leitura dos traços que integram cada um daqueles cenários, pode-se corroborar a tese realista e crítica que aponta para (re)configurações dos mercados de trabalho tendencialmente segmentados e desiguais.
A projecção de cenários sobre o futuro do trabalho depende de um conjunto de condições macroeconômicas, sociais e culturais, designadamente da divisão internacional do trabalho, das decisões políticas nas diversas matérias da sua intervenção, das condições do mercado dos produtos e do trabalho, dos sistemas de ensino e formação, das estratégias e conteúdos de negociação coletiva, entre outros aspectos ${ }^{3}$.

Estes cenários convocam todos os actores colectivos e individuais para imaginarem outros desafios e soluções criativas num projecto de regulação e cidadania pelo trabalho, assente em compromissos de corresponsabilidade e autonomia.

Por fim, estes cenários permitem destacar a relevância de estudos empíricos para se "buscar o trabalho" ${ }^{42}$ com o intuito de contribuir para uma "sociedade do trabalho renovada", em que o trabalho assume uma experiência social central para as mulheres e os homens reais que, de facto, trabalham.

\section{Notas finais:}

processos de ressimbolização do trabalho

Para este artigo, assumimos o pressuposto teórico de base de que o trabalho constitui um

Quadro 1. Cenários para a evolução do trabalho.

\begin{tabular}{|c|c|c|}
\hline+ & Cenário 3: Sociedade de trabalho renovada & Cenário 4: Sociedade de multiactividades \\
\hline \multirow{3}{*}{ 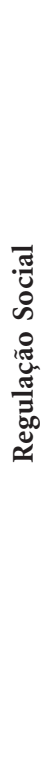 } & $\begin{array}{l}\text { Mercado de trabalho regulado } \\
\text {. Trabalho revalorizado pela articulação de } \\
\text { objectivos econômicos e sociais e pelas opções } \\
\text { técnico-organizacionais antropocêntricas } \\
\text {. Redução do tempo de trabalho } \\
\text {. Identidade e integração pelo trabalho } \\
\text {. Diálogo, participação e negociação }\end{array}$ & $\begin{array}{l}\text {. Sociedade de multiactividades e de tempos } \\
\text { escolhidos } \\
\text {. Trabalho reduzido e flexível } \\
\text {. Actividades alternativas } \\
\text {. Rendimento decente, regular não } \\
\text { dependente do emprego }\end{array}$ \\
\hline & $\begin{array}{l}\text { Cenário 1: Sociedade de trabalho regida pelo } \\
\text { mercado }\end{array}$ & Cenário 2: Sociedade de mercado \\
\hline & $\begin{array}{l}\text { Mercado de trabalho desregulado } \\
\text {. Trabalho: custo a ser reduzido } \\
\text {. Desemprego } \\
\text {. Precariedade do trabalho } \\
\text {. Dualização, diversificação, individualização } \\
\text { do trabalho } \\
\text {. Debilidade dos sindicatos } \\
\text { Espiral descendente de salários e condições } \\
\text { de vida }\end{array}$ & $\begin{array}{l}\text { Trabalho: custo a ser reduzido } \\
\text {. Desemprego } \\
\text {. Criação de novos empregos pela } \\
\text { mercantilização de todas as actividades } \\
\text { (serviços de proximidade) sujeitos a } \\
\text { precarização } \\
\text {. Debilidade dos sindicatos } \\
\text { Espiral descendente de salários e condições } \\
\text { de vida }\end{array}$ \\
\hline- & Centralidade do Trabalho & Centralidades de Actividades \\
\hline
\end{tabular}

Fonte: Kovács ${ }^{3}$ 
traço específico da espécie humana, uma dimensão estruturante e modal da vida social. O actual contexto de maior difusão de práticas de flexibilização laboral permitirá, provavelmente, que certos grupos de trabalhadores possam retirar daí vantagens em termos de melhoria das suas condições de remuneração, qualificação e conciliação da vida profissional com a familiar/pessoal; porém, para a maioria deles representará uma menor estabilidade ou segurança no emprego e, consequentemente, uma fragmentação e (des)estabilização da condição salarial que, no limite, pode conduzir ao desemprego por parte de diversas classes e categorias sociais e com impactos nas suas identidades.

Assim, com base no que temos vindo a argumentar, fruto da progressiva regressão do Estado, visível na não aplicação e/ou amputação de direitos sociais e serviços públicos subfinanciados, a par do acréscimo da complexidade e interdependência das actuais economias globalizadas e hipercompetitivas, podemos sistematizar quatro processos de ressimbolização do mercado de trabalho em curso $^{20}: 1$ ) adoção, em simultâneo, de uma "cultura de risco" e de "incerteza", com exigências de compromisso, fidelidade e confianças exigidas aos atores sociais $\left.{ }^{12} ; 2\right)$ lógicas de intensificação e racionalização subtis dos modelos de organização do trabalho patentes nas estratégias de "mercantilização" das relações de trabalho; 3 ) transformação da ideia e prática de "carreira" profissional que deixa de se fazer exclusivamente numa lógica de mobilidade intraempresa, para incluir percursos e trajectórias de vida baseados numa crescente mobilidade transversal às empresas em contexto nacional e internacional; 4) recolocação da perspectiva individualista e tendencialmente "desinstitucionalizada" em relação aos sistemas educativo e emprego face às exigências de uma empregabilidade permanente dos trabalhadores.

Desta sistematização dos processos de ressimbolização do trabalho e emprego importa ter presente que os mesmos concorrem para uma crescente "dualização social" e fragmentação das relações de trabalho, com incluídos e excluídos, estáveis e precários, empregados e desempregados, activos e inactivos, jovens e idosos, entre outros. A quebra de solidariedade entre estes diferentes grupos, que pode exprimir, em simultâneo, vários daqueles processos de dualização, contribui para o acréscimo de desigualdades sociais e para a "crise" do Estado Social. 


\section{Referências}

1. Boltanski L, Chiapello È. Le Nouvel Esprit du Capitalisme. Paris: Gallimard; 1999.

2. Kovács I, organizador. Flexibilidade de Emprego: ris cos e oportunidades. Oeiras: Celta Editora; 2005.

3. Kovács I. As Metamorfoses do Emprego. Ilusões e Problemas da Sociedade da Informação. Oeiras: Celta Editora; 2002.

4. Santos BS, editor. Globalização. Fatalidade ou Utopia. Porto: Afrontamento; 2001.

5. Esping-Andersen G, Regino M, editor. Why Deregulate Labour Markets? Oxford: Oxford University Press; 2000.

6. Beck U. Un nuevo mundo feliz. La precaried del trabajo en la era de la globalización. Barcelona: Piados; 2000.

7. Giddens A. A Europa na era Global. Lisboa: Editorial Presença; 2007.

8. Boyer R, Drache D, editor. Estados contra mercados: os limites da globalização. Lisboa: Instituto Piaget; 1997.

9. Boyer R, Freyssinet M. Les Modeles Produtifs. Paris: Editions de la Découverte; 2000

10. Boyer R, coordenador. La Flexibilité du travail en Europe. Paris: La Découverte; 1986.

11. Dubar C. La crise des identités. L'interprétation d'une mutation. Paris: PUF; 2000. [Collection Le lien social]

12. Sennett R. A corrosão do carácter: as consequências pessoais do trabalho no novo capitalismo. Lisboa: Terramar; 2001.

13. Sennett R. Le travail sans qualités. Paris: Albin Michel; 2000.

14. Giddens A. As Consequências da Modernidade. Oeiras: Celta Editora; 1992.

15. Cordellier S, Doutant F, organizadores. A globalização para lá dos mitos. Lisboa: Editorial Bizâncio; 1998.

16. Blossfeld HP, Klilking E, Mills M, Kurz K, editors. Globalization, Uncertainty and Youth in Society. London, New York: Routledge; 2005.

17. Kovács I, Castilho J. Novos modelos de produção: trabalho e pessoas. Oeiras: Celta Editora; 1998.

18. Wichert I. Job Insecurity and Work Intensification: The Effects on Health and Well-Being. In: Burchell B, Lapido D, Wilksion F, editors. Job Insecurity and Work Intensification. London: Routledge; 2002.

19. Gollac M, Volkoff S. Les conditions de travail. Paris: Editions la Découverte; 2000.

20. Marques AP. Sacralização do mercado de trabalho. Jovens diplomados sob o signo da precariedade. Revista Configurações - Trabalho e Não trabalho: valor e (in)visibilidade 2010; (7):65-89.

21. Fitoussi JP, Rosenvallon P. A nova era das desigualdades. Oeiras: Celta Editora; 1997.

22. Reich R. O trabalho das nações. Lisboa: Ed. Questzal; 1993.

23. Estanque E. Classes Médias. Ascensão e Declínio. Lisboa: Edição Fundação Francisco Manuel dos Santos (FFMS); 2011.

24. Tremblay DG, editor. Flexibilité, sécurité d'emploi et flexicurité. Quebec: Presses l'Université du Quebec; 2008
25. Oliveira L, Carvalho H. Precarious employment in Europe. Dados - Revista de Ciências Sociais 2008; 55(3):541-567.

26. Auer P. Mobilidade protegida para o emprego e o trabalho digno: segurança no mercado de trabalho num mundo globalizado. Rev. Sociedade e Trabalho 2006; 27:45-56

27. Feltead A, Jewson N. Global Trends in Flexible Work. London: Macmillan Press Lda.; 1999.

28. Marques AP. Recrutamento e gestão da transição de graduados: o olhar dos empregadores da Região Norte. In: Marques AP, Alves MG, editores. Inser ção Profissional de Graduados em Portugal. (Re)configurações Teóricas e Empíricas. Vila Nova de Famalicão: Editora Humus Lda., CICS - Universidade do Minho; 2010. p. 259-286.

29. Marques AP. MeIntegra - Mercados e estratégias de inserção profissional. Licenciados versus empresas da Região Norte. [Relatório final]. Colecção DS/CICS. Braga: Universidade do Minho; 2007. [acessado 2013 abr 23]. Disponível em: http://hdl.handle.net/1822/ 8633

30. Marques AP. Entre o diploma e o emprego. A inserção profissional de jovens engenheiros. Porto: Afrontamento; 2006

31. Marques AP. Mercados profissionais e (di)visões identitárias entre jovens engenheiros. Sociologia 2005; (14):165-194

32. Marques AP, Moreira R. Transição para o mercado de trabalho: empreendedorismo numa perspectiva de género. In: Actas do XVII Encontro Nacional de SIOT - Emprego e Coesão Social: Crise de regulação e hegemonia da globalização; 2011; APSIOT, Lisboa. Edição em Cd-Rom.

33. Pollert A. L'entreprise flexible: réalité ou obsession? Sociologie du travail 1989; 31(1):75-106.

34. Organização para a Cooperação e Desenvolvimento Económico (OCDE). La Flexibilité du Marché de Travail - Le Débat d'Aujourd'hui. Paris: OCDE; 1986.

35. Focaurde B. L'evolution des situations d'emploi particuliéres de 1945 a 1990. Travail et Emploi 1992; 52:4-19.

36. Castel R. Les métamorphoses de la question sociale. Une chronique du salariat. Paris: Fayard; 1995.

37. Buchell B, Lapido D, Wilkinson F, editores. Job Insecurity and Work Intensification. London: Routledge; 2002.

38. Méda D. Le travail. Une valeur en voie de disparition. Paris: Aubier; 1995

39. Rifkin J. La fin du travail. Paris: La Découverte, Poche; 1997.

40. Bidet J, Texier J, organizadores. La Crise du travail. Paris: PUF; 1995

41. Paugam D. Le salarié de la précarité. Paris: PUF, 2000.

42. Castillo JJ, editor. El Trabajo del Futuro. Madrid: Editorial Complutense; 1999.

Artigo apresentado em 08/11/2012

Aprovado em 25/012013

Versão final apresentada em 14/02/2013 